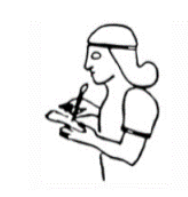

\begin{tabular}{|l|l|l|l|}
\hline ARCHIVUM ANATOLICUM (ArAn) & $15 / 2$ & 2021 & $415-430$ \\
\hline
\end{tabular}

BOĞAZKALE ARŞIVINDEN YENI HITITTÇE FRAGMANLAR

\author{
Gülgüney MASALCI ŞAHİN* \\ Ismet $A Y K U T^{* *}$ \\ Özlem SIR GAVAZ ${ }^{* * *}$
}

Makale Bilgisi

Başvuru: 15 Kasım 2021

Kabul: 29 Kasim 2021

Article Info

Makale Türü: Araştırma Makalesi

$\ddot{\boldsymbol{O}} z$

Çalışmada tanitılacak tabletler, 1987 yllında Berlin'den Türkiye'ye, Ankara Anadolu Medeniyetleri Müzesi'nel geri getirilen fragmanlardandır. Hititçe tablet fragmanlarl dini içerikli olup, çalışmada, Bo 7825, Bo 7881, Bo 8141 ve Bo 8168 nolu tablet fragmanlarinin transliterasyonu ve tercümesi verilecek, filolojik yorumu yapılacak ve seri içindeki yeri belirlenecektir.

Anahtar Kelimeler: Hititler, Boğazkale, çivi yazılı tabletler, din.

New Hittite Fragments from the Boğazkale Archive

\title{
Abstract
}

The tablets to be introduced in this study are the fragments that were returned to Ankara Anatolian Civilizations Museum from Berlin in 1987. Tablet fragments have religious contents and in this paper the transliteration and translation of those numbered Bo 7825, Bo 7881, Bo 8141 and Bo 8168 will be given, and a philological interpretation and a series description will be made.

Keywords: Hittites, Boğazkale, cuneiform tablets, religion

* Dr. Öğretim Üyesi, Bilecik Şeyh Edebali Üniversitesi, Fen Edebiyat Fakültesi, Tarih Bölümü, gulguney.masalci@ bilecik.edu.tr ; ORCID: 0000-0003-2692-874X

** Hititolog, Ankara Anadolu Medeniyetleri Müzesi, ismetaykut86@gmail.com; ORCID:0000-0001-8799-1377

**** Doç. Dr., Ankara Üniversitesi, Dil ve Tarih- Coğrafya Fakültesi, Eskiçağ Dilleri ve Kültürleri Bölümü, Hititoloji Anabilim Dalı, gavaz@ ankara.edu.tr ; ORCID: 0000-0001- 6671-6691

1 Bu makalede tanıttığımız tabletleri yayımlamamıza izin veren Anadolu Medeniyetleri Müzesi Müdürü Sayın Yusuf Kıraç'a, yardımları için müzenin tablet seksiyonu çalışanlarına ve fotoğraf çekimindeki desteklerinden dolayı Ahmet Remzi Erdoğan'a teşekkürlerimizi sunarı. 


\section{Bo 7825}

Açık kahve rengi olan fragman, tabletin orta kısmına aittir. Tablet parçasının uzunluğu $4.2 \mathrm{~cm}$, genişliği $2.3 \mathrm{~cm}$ ve kalınlığ $0.8 \mathrm{~cm}$ 'dir. Bo 7825, CTH 652'de Firtına Tanrisinin adamından bahseden bayram fragmanlarına ait bir tablet parçasıdır. Košak, CTH 652'de; Bo $2381+$ Bo $3470+$ Bo 7825+ Bo 8281+ Bo 10096+ VAT 13589 şeklinde sınıflandırmıştır².

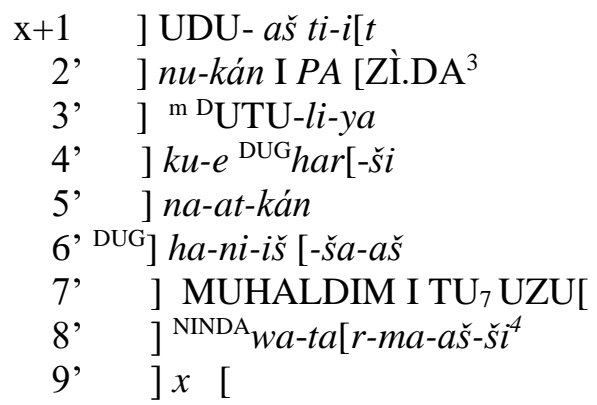

\section{Filolojik Yorum}

$\mathbf{x + 1}$ UDU: koyun

St. 2' $\boldsymbol{P A}=P A R \bar{I} S U^{\prime}$ nun kısa yazılışı: Bir ölçek ${ }^{5}$

St. 3' m DUTU-liya Erkek şahıs ismi. ${ }^{6}$ m ${ }^{D}$ UTU-LÚ Tiwataziti $^{7}$ olarak okunduğundan ${ }^{\mathrm{m}} \mathrm{D}$ UTU-liya Tiwataliya olarak tarafımızdan okunmuştur.

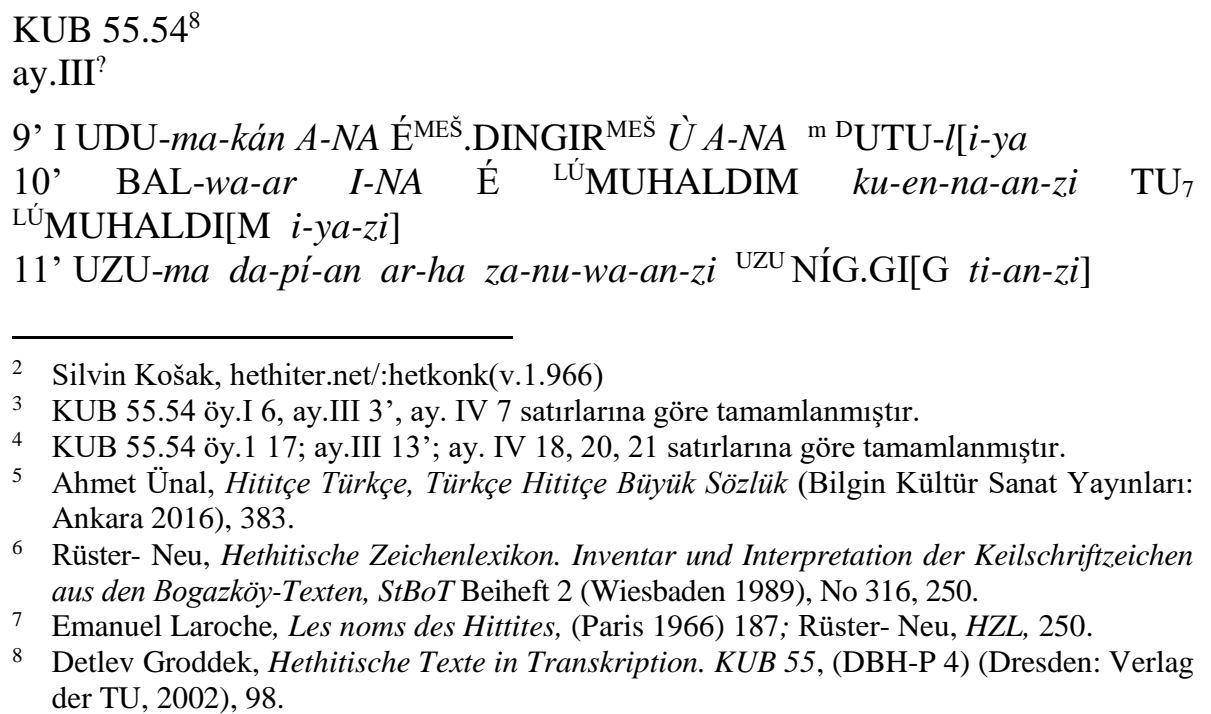


12' [ma-a-a]n-ma-kán $\mathrm{TU}_{7}{ }^{\text {HI.A }} a-r i$ nu NAG-na SUM-an-zi[

13' [ ] ${ }^{\text {MEŠ }} \check{S} A 1 / 2$ BÁN III ${ }^{\text {NINDA }}$ wa-tar-ma-aš-ši-uš $1 / 2$ BÁN III NINDA. [TU $\left.\mathrm{TU}_{7} U P-N I\right]$

9' Bir koyun ise tanrıların tapınaklarına ve Tiwatal[iya' ya

10' kurban etmek için mutfakta öldürürler. Aşçı çorbayı hazırlar.

11' Etin hepsini dışarıda pişirirler. Karaciğer[i koyarlar.]

12 ' Etler var[1nca] içkiyi verirler.

13' [ ] ].., üç watarmašši ekmeğin yarısı, üç etli ekmeğin yarısı

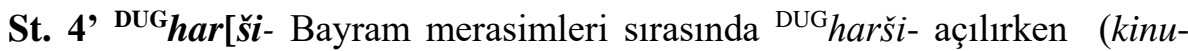
/genu- $)^{9}$ ya da doldurulurken (šuhha-/ išhuwai-) ${ }^{10}$ geçmektedir. Bayramda takdim edilen yiyecek ve içecekler, genellikle DUGharši ile yan yana siralanmaktadır ${ }^{11}$. KUB 1737 I 4'-5' de aynı bizim burada tanıttığımız Bo 7825 'de olduğu gibi ${ }^{\mathrm{DUG}}$ harši- ve ${ }^{\mathrm{DUG}}$ haniššaš art arda sıralanmıştır ${ }^{12}$.

St. 6, DUG hanišša- DUG haneššar/hanešša-/haniša- "Bir kap, kepçe"13 Bu kap Coşkun'a göre kültte ikinci derecede öneme sahip, çok kullanılan bir tür "toplama kabı"dır"

St. 7' (LÚ/MUNUS)MUHALDIM "aşçı"15. Hititçe metinlerde saray ve tapınak görevlisi olarak karşımıza çıkmaktadır. Hem tapınakların önemli kült görevlileri olan "hilammatta"lar, hem de Éhešta'nın kült görevlileri arasında yer alan LÚMUHALDIM'in Hititçe karşılığı net olarak bilinmese de Hattice

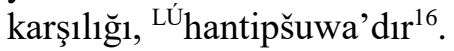

$\mathbf{T U}_{7}$ UZU "et yemeği". ${ }^{17} \mathrm{TU}_{7}$ "çorba, çorba adları önüne gelen determinatiftir" ${ }^{18}$. Hititçe metinlerde et yemekleri, etin suda kaynatılmas1 ya

9 Johannes Friedrich, Hethitisches Worterbuch (Heidelberg: Carl Winter, 1952), 60; Ahmet Ünal, Ahmet, Multilinguales Handwörterbuch des Hethitischen / A Concise Multilingual Hittite Dictionary/ Hititçe Çok Dilli El Sözlüğü (Kovač: Hamburg 2007), 344.

10 Ünal, Multilinguales Handwörterbuch, 271; 647.

11 Yaşar Coşkun, Boğazköy Metinlerinde Geçen Bazı Seçme Kap İsimleri, Yayınlanmamış Doçentlik Tezi, (Ankara, 1974) 16.

12 KUB 17.37 I

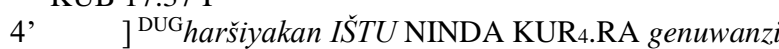

5, DUG hani] ̌̌šaš KAŠ DUG harši genuwaš

Metin yeri transliterasyonu için bkz. Coşkun, Bazı Seçme Kap İsimleri, 16.

13 Friedrich, $H W$, 50; Ünal, Multilinguales Handwörterbuch, 158.

14 Coşkun, Bazı Seçme Kap Ísimleri, 35.

15 Neu- Rüster, HZL, 338; M.Weeden, Hittite Logograms and Hittite Scholarship (Wiesbaden: Harrassowitz Verlag, 2011), 583; Ünal, Hititçe-Türkçe Büyük Sözlük, $356 \mathrm{dv}$.

16 Bu bilgi ve daha fazla ayrıntı için bkz. Hatce Baltacıŏglu, Alaca Höyük Sfenksli Kapı Aşçılar Kabartması, Archivum Anatolicum VI/1: 59-131.

17 Rüster- Neu, HZL, 354; Ünal, Hititçe-Türkçe Büyük Sözlük, 543. 
da açık alevde ve kömürde pişirilmesi ile hazırlanmaktadır. Etin haşlanmasiyla elde edilen et suyu metinlerde "sulu et yemeğii" ${ }^{\mathrm{TU7}} \mathrm{A} . \mathrm{UZU}$ olarak geçmektedir ${ }^{19}$. Fakat önüne gelen determinatiften dolayı $\mathrm{TU}_{7}$ UZU'nun da sulu bir et yemeği olması muhtemeldir.

St. 8, ${ }^{\text {NINDA }}$ watarmašši- "bir ekmek çeşidi”. ${ }^{20} \mathrm{CTH} 678$ Nerik Kenti kültüne ait bayram fragmanlarından KUB 54. 94 st.10' $\mathrm{da}^{21}$ ve CTH 652 KUB 55.54 I 17, III 13, IV 18, 20, 21'”de ${ }^{22}$ geçmektedir.

\section{Bo 7881}

Kiremit rengi olan fragman, tabletin orta kısmına aittir. Tablet parçasının uzunluğu $4.1 \mathrm{~cm}$, genişliği $7.1 \mathrm{~cm}$ ve kalınlığı $1.7 \mathrm{~cm}$ 'dir.

ay. III

$\mathrm{x}+1] \quad] z i[\mathrm{x}$

2, MU $]^{\mathrm{NUS} . M E S ̌ ~ K A x G A G ~} h[a-a t-t a-a n-t e-e s ̌ c]$

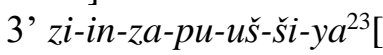

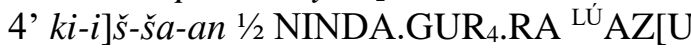

5' ]-i 1/2-ma ar-ha pár-ši-ya [

6' $p a ́] r-\check{s} u-u l-l i^{24} A-N[A]$ EN SISKUR.SISKUR ${ }^{25}$

2' KAxGAG $h[$ attant- $]$ kadınları

3' güvercin [şarkısını]

4' bu ]şekilde yarım kalın ekmeği AZ[U

5' ] yarısını dışarıda parçalar [

18 Rüster-Neu, HZL 354.

19 Ahmet Ünal, Hitit Başkenti Hattuša'da Otuz Bin Koyunlu, On Bin Boğalı ve Bol İçkili Büyük Şölen Eski Anadolu'nun 3500 Yıllık Yemek ve İçkileri, (Ankara: Bilgin Kültür Sanat Yayınlar1 2019),293,295.

20 Ünal, Multilinguales Handwörterbuch, 2007, 97. Harry A. Hoffner Jr., Alimento Hethaeorum, Food production in Hittite Asia Minor (New Haven:American Oriental Society, 1974),175, 190; Ünal, Büyük Şölen Eski Anadolu'nun 3500 Ylllık Yemek ve İçkileri, 312.

21 Heinrich Otten, Rev. of: Klengel H. 1984 (Keilschrifturkunden aus Boghazköi 54 Hethitische Rituale und Festbeschreibungen), ZA 75 (1985), 142-145, 145.

22 Groddek, Hethitische Texte in Transkription. KUB 55, 96-98.

23 Ünal, Multilinguales Handwörterbuch, 823.

24 Ünal, Multilinguales Handwörterbuch, 527.

25 KUB 47.65 ay IIII st 1. Joini ile tamamlanmıstır. Wegner Ilse Wegner, Hurritische Opferlisten aus hethitischen Festbeschreibungen, Teil 1: Texte für ISTAR-Sa(w)uska (ChS 1/3/1 ) (Roma 1995), s.182'de EN.SISKUR şeklinde yayınlamıştır. Tarafımızdan EN.SISKUR.SISKUR şeklinde okunmuştur. 
6'ekmek parçasını kurban beyi [ne]

\section{Filolojik Yorum}

St. 2, Munus . ${ }^{\text {MEš }}$ KAxGAG hattant ${ }^{26}$ anlamı tam olarak bilinemeyen bir kadın meslek grubudur. ${ }^{27}$

KUB 47.65 numaralı metin Bo 7881 ile joindir ${ }^{28}$ ve burada sözü geçen kadın grubu görülebilmektedir.

\section{KUB $47.65^{29}$}

ay. III

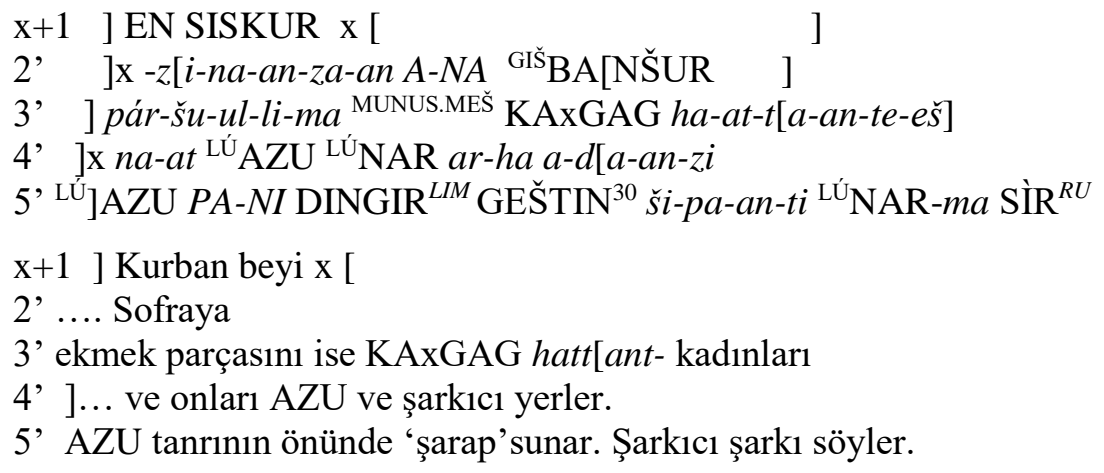

St.3’ zinzappu- bir kuş, güvercin; zinzapušši-/zinzawušši- güvercin şeklinde bir riton, kap. ${ }^{31}$

Metnin başı kırık olduğu için SìR $^{32}$ sözcüğü ile geçmiş olabilir. SìR ${ }^{\mathrm{HI} . \mathrm{A}}$ zinzapuššiyaš "güvercin şarkılart" anlamına gelir. ${ }^{33}$ CTH 276 katalog numaralı tablet katalogların belirten bir metin dizisinde, bu terim görülmektedir:

\footnotetext{
26 Franca Pecchioli Daddi, Mestieri Professioni E Dignità Nell'Anatolia Ittita (Roma: Edizioni dell'Ateneo 1982), 414-415.

27 Ünal, Hititçe Türkçe, Türkçe Hititçe Büyük Sözlük, 245.

28 Bkz Devlet Groddek, "Über Joins und Joinen. Aus der Arbeit an der Hinterlassenschaft der hethitischen Archive und Bibliotheken", IJDL 2 (2005) 1-28, 18.

29 Wegner $C h S$ 1/3/1, 182.

30 Wegner'in transliterasyonunda (Wegner $C h S$ 1/3/1, 182) GEŠTIN bulunmamaktadır. Bu kısım tarafımızdan eklenmiştir.

31 Ünal, Hititçe Türkçe, Türkçe Hititçe Büyük Sözlük, 609.

32 Şark1 söylemek, ilahi, müzik parçası, şarkı, destan, epope (Friedrich, HW, 292; NeuRüster, $H Z L, 348$ ).

33 Ahmet Ünal, Hititlerde Din, Devlet, Halk ve Eğlence, (Ankara: Bilgin Kültür Sanat Yayınları 2019), 179.
} 
KUB 8.69 III $^{34}$

1 DUB 1.KAM SÌR ${ }^{\mathrm{HI} . \mathrm{A}} z i-i n-z a-p u-u s ̌-s ̌ i-y[a-a s ̌ s]$

$2 \check{S} A^{\mathrm{D}}$ ISTAR ${ }^{\mathrm{URU}} \mathrm{Ni-nu-} \quad$ wa

1-2 Ninuwa'nın Ištar'ının güvercin şarkıları birinci tableti

KUB $8.73^{35}$

2 DUB 1.KAM $Q A-T I n u-u \check{s}-s ̌ a-a n A-[N A \quad]$

$3 z i-<i n>-z a-p u-u \check{s}-s ̌ i-y a-a \check{s} \quad \mathrm{x}[\quad]$

4 DUB.1.KAM QA-TI BAD-an [ ${ }^{\mathrm{D} I S T A R} \overline{\mathrm{URU}} N i-n u-w a$ ]

5 KAxGAG ha-at-t[a-an-

2-3 Ninuwa'nın Ištar'ının güvercin şarkıları birinci tableti

4 [Ninuwa'nın Sahibesi Tanrıça Ištar'ın] güvercin şarkıları birinci tableti bitti.

5 KAxGAG hattant-

Hitit dilinde kaydedilmiş Ninuwa'nın Ištar'i için gerçekleştirilen festivalde, güvercin adaklarıyla güvercin festivali törenleri, güvercin biçimli kült kapları ve Hurri dilinde "güvercin şarkıları" okunuşları gerçekleşmiştir ${ }^{36}$.

St. 4' kiššan : Hit. zarf "bu şekilde, böylece, böyle, aşağıdaki şekilde"37

NINDA.GUR 4.RA: Kalın ekmek, somun ${ }^{38}$.

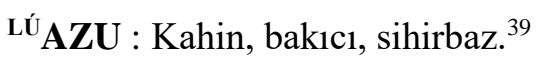

St. 5' parš- /parši-/paršai-/paršiya- parçalamak, bölmek, dağıtmak, bozmak, kırıp dağıtmak. ${ }^{40}$

34 Ilse Wegner, Hurritische Opferlisten aus hethitischen Festbeschreibungen, Teil 1: Texte für ISTAR-Sa(w)uska Roma 1995 ChS 1/3/1 s.172.

35 Wegner, ChS 1/3/1 s.172.

36 Volkert Haas, Geschichte der Hethitischen Religion (Leiden, New York, Köln: Brill. 1994), 361.

37 Friedrich, HW,111; Ünal, Hititçe Türkçe, Türkçe Hititçe Büyük Sözlük, 283.

38 Friedrich, $H W$, 288; Johann Tischler, Hethitisches Handwörterbuch, Mit dem wortschatz der Nachbarsprachen (Innsbruck Institut Für Sprachwissenschaft der Universität: Innsbruck 2001), 250; Ünal, Multilinguales Handwörterbuch, 486.; Ünal, Hititçe- Türkçe Türkçe Hititçe Büyük Sözlük, 376; Mark Weeden, Hittite Logograms and Hittite Scholarship (StBoT 54 Wiesbaden: Harrassowitz Verlag 2011), 534.

39 Rüster-Neu, HZL, 308; Pecchioli Daddi, Mestieri, 290-297; Ünal, Hititçe- Türkçe Türkçe Hititçe Büyük Sözlük, 99.

40 Friedrich, HW, 163; Ünal, Hititçe Türkçe Türkçe Hititçe Büyük Sözlük, 403. 
arha paršiya dişarıda parçalar.

St. 6' ${ }^{(\text {NINDA) }}$ páršulli-/paršul-/paršiulli-/paršuil- "bir çeşit ekmek ya da ekmek parçasi/kırıntısı". ${ }^{41}$ parš-/parši-/paršai-/paršiya- fiiliyle ilişkilendirilen bu ekmek ulli- deverbal substantiv eki ile "kırılmış, ekmek kırıntısı olarak çevrilmiştir. ${ }^{42}$

EN SISKUR.SISKUR :Kurban sahibi ${ }^{43}$

$\mathrm{Bu}$ tablet fragmanında güvercin (şarkıları ya da güvercin festivali törenleri) yukarıda değinildiği gibi Ninive'nin İštar'ına ait törenlerle özdeşleşmiştir ve yine KAxGAG hattant- kadınları Ištar'ın bayram ritüellerine ait bir fragman olduğunu gösteren terimlerdendir.

\section{Bo 8141}

Açık kahve rengi olan fragman, tabletin orta kısmına aittir. Tablet parçasının uzunluğu $3.9 \mathrm{~cm}$, genişliği $2.8 \mathrm{~cm}$ ve kalınlığı $1.6 \mathrm{~cm}$ 'dir.

$$
\begin{aligned}
& \mathrm{x}+1 \quad r] i \quad[ \\
& \text { 2, ] } \\
& \text { 3' ma-ni]-ya-ah-hi-uš } \\
& \text { 4' n]a-aš LUGAL-wa [-a } \\
& \text { 5' la-ba-ar-(?)] }{ }^{44} \text { na-an }
\end{aligned}
$$

\section{Filolojik Yorum}

St. 3' ma-ni]-ya-ah-hi-uš : maniyahhai- "idare, yönetim, idare bölgesi”, pl. acc. com. ${ }^{45}$

(CTH 821.1 )Kraliyet ve Tanrısal adalet ile ilgili bir tablet fragmanıdır. IBoT 1.30 (+Bo 2018) ile metnin tamamı öğrenilebilmektedir.

IBoT $1.30{ }^{46}$

1 [LUGAL]-uš $k u$-wa-pi DINGIR ${ }^{\mathrm{MEŠ}}$ - aš $a-r u-w a-a-i z-z i{ }^{\text {LÚGUDÚ } k i s ̌-a n}$ ma-al-di

41 Friedrich, HW, 164; Ünal, Hititçe Türkçe- Türkçe Hititçe Büyük Sözlük, 404 vd.

42 Harry Angier Hoffner Jr., , Alimento Hethaeorum, Food production in Hittite Asia Minor, (New Haven: American Oriental Society, 1974), 176; Güngör Karauğuz, Hititler Dönemi'nde Anadolu'da Ekmek (Arkeoloji ve Sanat Yayınları, İstanbul 2006), 85.

43 Rüster-Neu, HZL, 316; Ünal, Hititçe Türkçe- Türkçe Hititçe Büyük Sözlük, 437.

44 IBoT 1.303.

45 A. Ünal, Hititçe Büyük Sözlük, 2016, 336 vd.

46 Albrecht Goetze, Rev. of:Bozkurt H et al. 1944, JCS 1 (1947), 90-91. Ada Taggar- Cohen, Hittite Priesthood(THeth 26, Heidelberg 2006) $253 \mathrm{vd}$. 
2 ta-ba-ar-na-an-kan LUGAL-uš DINGIR $\mathrm{MEŠs}_{-a s ̌} a$-aš-šu-uš $e$-eš-du KUR$e^{\mathrm{D}} \mathrm{U}-\mathrm{aš}-$ pát

3 ne-pí-eš te-kán-na ÉRIN ${ }^{\mathrm{MES}}{ }_{-} a z$ ' ${ }^{\mathrm{D}} \mathrm{U}-a{ }^{5}-p a ́ t ~ n u-z a$ la-ba-ar-na-an

LÚLUGAL-un

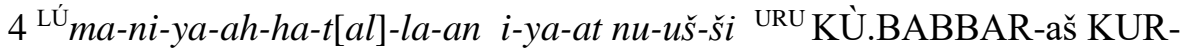

$e$

5 hu-u-ma-an pa-iš [nu-uš] $-s ̌ a-a n$ KUR-e hu-u-ma-an la-ba-ar-na-aš

6 ŠU-az ma-ni-[ya-ah-hi-i] š-ki-id-du ku-iš-ša-an

7 la-ba-ar-n[a-aš LUGAL-wa-ašs] NÍ.TE-aš ir-ha-aš-ša

$8 \check{s} a-l i-g[a-r i \quad n a-a] n{ }^{\mathrm{D}} \mathrm{U}-a \mathrm{~s}$ har-ni-ik-du

1 [Kral] tanrıların önünde eğilince, tazelli rahibi şöyle okur:

2 'Kral Tabarna, tanrılara (karşı) iyi ol. Ülke Fırtına tanrısı(nındır);

3 Gökyüzü, yeryüzü ve askerler Fırtına tanrısı(nındır). Ve Kral Labarna'yı

4 yönetici kral yaptı, Hattuša ülkesinin

5 tümünü (ona) verdi. [Ve] Labarna tüm ülkeyi

6 Elinden (eliyle) yönetsin. Kim

7 Labarna'nın kendisine ve sinırına

8 yaklaşırsa onu Furtına tanrısı yok etsin!

IBoT 1.30, geç bir versiyon olmakla birlikte orijinali eski Hitit dönemine dayanıyor olmalıdır. Metnin dublikatı olan KUB 48.13 ay. 9 vd. Hattice rezitasyonlar içeren bir festival fragmanıdır. Başka bir dublikat olan KUB 54.64'te, Nerik ve Zahalukka şehirleri geçmektedir. Dolayısıyla Bo 8141 de Eski Hitit dönemine ait bir belgenin geç dönem kopyası olmalıdır. ${ }^{47}$ Metinde krala ülkeyi ve yöneticiliği tanrının bahşettiği vurgulanmaktadır. ${ }^{48}$

\section{Bo 8168}

Açık kahve rengi olan fragman, tabletin sol orta kısmına aittir. Tablet parçasının uzunluğu $6.4 \mathrm{~cm}$, genişliği $3.8 \mathrm{~cm}$ ve kalınlığ $2.5 \mathrm{~cm}$ 'dir.

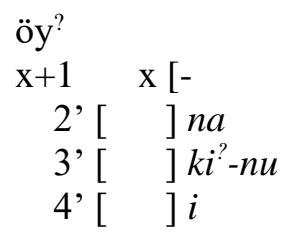

47 Jörg Klinger, Untersuchungen zur Rekonstruktion des hattischen Kultschicht StBoT 37 (Wiesbaden 1996), 137, d.n. 39.

48 Ayrıntılı bilgi için bkz. Sylvia Hutter- Braunsar, "Elemente der hethitischen Herrscherlegitimation in hethitischen historiographischen Texten",Ed. Sedat Alp, Aygül Süel, III.Uluslararası Hititoloji Kongresi Bildirileri (Ankara 1998), 331-339. 


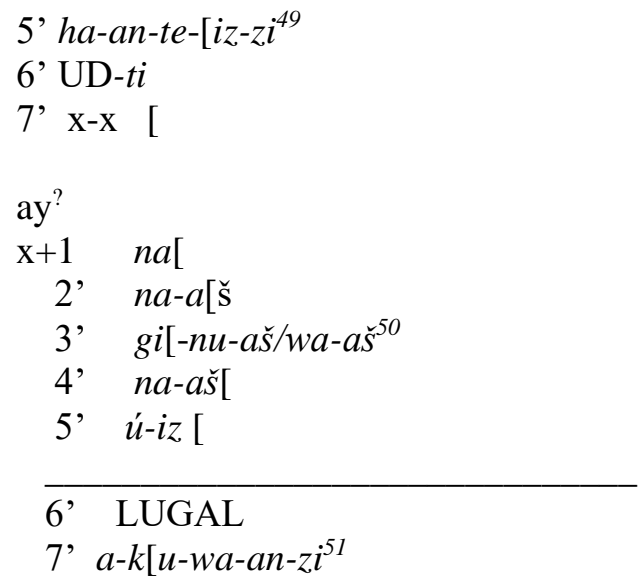

\section{Filolojik Yorum}

öy.

5' hantezzi- hantezziya - "ilk, en başta, en önde bir şeyin önünde, en iyisi, birinci sinıf, kaliteli",52

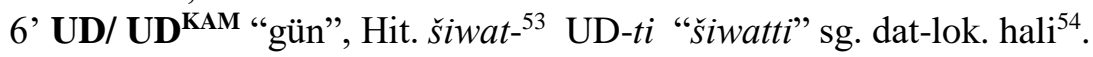

ay.

5' úizzi : uwa- "gelmek, ulaşmak, varmak, vasıl olmak" prs. 3. Tekil şahıs "gelir" "55

Tablet fragman1, KUB $12.54^{56}$ 'le join olabilmektedir. Bu bakımdan Bo $8168^{\prime}$ 'in de CTH $659^{57}$ 'a, Tahta çıkma festivaline konu olan fragmanlara ait olduğunu söyleyebiliriz.

49 KUB 12.54 ay. 1 '

50 KBo 52.131 + IBoT 4.95 öy. I 39' a göre tamamlanmıştır. Alice Mouton, "La fête dite de l'intronisation CTH 659”, Ed. Šarka Velharticka, Audias fabulas veteres.Anatolian Studies in Honor ofJana Součkova-Siegelova ( Brill: Leiden, Boston 2016), 239.

51 KUB 46.4 öy. I 25'e göre tamamlanmıştır. Mouton, CTH 659, 239.

52 Ünal, Hititçe Büyük Sözlük, 151 vd.

53 Ünal, Hititçe Büyük Sözlük, 558.

54 Ahmet Ünal, Hititçe Dilbilgisi. Çivi Yazısı Issaret Listesi ve Çok Sayıda Okuma Parçalarıyla Birlikte (Bilgin Kültür Sanat Yayınları: Ankara, 2019), 145.

55 Ünal, Hititçe Büyük Sözlük, 572.

56 Daisuke Yoshida Untersuchungen zu den Sonneingottheiten bei den Hethitern, Schwurgötterliste, helfende Gottheit, Feste, (THeth 22), (Heidelberg: C. Winter 1996), 197; Alice Mouton, CTH 659, 234 vd.

57 Mouton, La fête dite de l'intronisation CTH 659, 233-256. 


\section{Sonuç}

Burada incelediğimiz Bo 7825, Fırtına Tanrısı'nın adamından bahseden bir bayram metni fragmanıdır. KBo 52.128, KUB 55.54, DBH 43/2 13 ile ilişkilendirilmiştir.

Bo 7881 nolu fragman, KUB 47.65 ile join yapılmış̧ır. Muhtemelen, Ninuwa'nın Ištar' 1 için gerçekleştirilen festivalde, güvercin adaklarıyla, güvercin şarkılarının söylendiği bir töreni konu almaktadır. Ayrıca görevleri tam olarak tespit edilmemiş olan MUNUS.MEŠKAXGAG hattant- kadınlarının bu törenlerde etkin rol aldıkları anlaşılmaktadır.

Bo 8141, IBoT 1.30 ile ilişkilidir. Bu Hititçe fragman, Eski Hitit dönemine ait bir belgenin geç dönem kopyası olmalıdır. Metinde Fırtına Tanrısı'nın tüm ülkeyi krala verdiği ve kralın yetkilerini tanrıdan aldığı belirtilmiştir

Son olarak, Bo 8168 nolu fragman, tahta çıkma seremonisini konu almaktadır ve KUB 12.54 ile join olmaktadır. 


\section{KAYNAKÇA}

Coşkun, Yaşar, Boğazköy Metinlerinde Geçen Bazı Seçme Kap Ísimleri, Yayınlanmamış Doçentlik Tezi, Ankara, 1974.

Friedrich, Johannes, Hethitisches Worterbuch, Heidelberg: Carl Winter, 1952.

Haas, Volkert, Geschichte der Hethitischen Religion, Handbuch der Orientalistik. Der Nahe und Mittlere Osten 15, Leiden, New York, Köln: Brill. 1994.

Hoffner Jr., Harry Angier, Alimento Hethaeorum, Food production in Hittite Asia Minor, New Haven: American Oriental Society, 1974.

Goetze, Albrecht, Rev. of:Bozkurt H et al. 1944 (Bozkurt H. - Çiğ M. - Güterbock H.G., Ístanbul Arkeoloji Müzelerinde Bulunan Boğazköy Tabletlerinden Seçme Metinler Ausgewählte Texte aus den Boğazköy- Tafeln in den Istanbuler Archäologischen Museen, İstanbul), JCS 1, 1947. 87-92.

Groddek, Detlev, "Über Joins und Joinen. Aus der Arbeit an der Hinterlassenschaft der hethitischen Archive und Bibliotheken", International Journal of Diachronic Linguistics and Linguistic Reconstruction 2 (2005) 1-28, 18.

Groddek, Detlev, Hethitische Texte in Transkription. KUB 55, (DBH-P 4) (Dresden: Verlag der TU, 2002)

Hutter- Braunsar, Sylvia, "Elemente der hethitischen Herrscherlegitimation in hethitischen historiographischen Texten”,Ed. Sedat Alp, Aygül Süel, III.Uluslararası Hititoloji Kongresi Bildirileri, Ankara 1998, 331-339.

Karauğuz, Güngör, Hititler Dönemi'nde Anadolu'da Ekmek Arkeoloji ve Sanat Yayınları, İstanbul 2006.

Klinger, Jörg, Untersuchungen zur Rekonstruktion des hattischen Kultschicht StBoT 37, Wiesbaden 1996.

Košak, Silvin hethiter.net/:hetkonk(v.1.966)

Mouton, Alice "La fête dite de l'intronisation CTH 659", Ed. Šarka Velharticka, Audias fabulas veteres.Anatolian Studies in Honorof Jana SoučkovaSiegelova, Leiden, Boston: Brill 2016, 233-256.

Otten, H. Rev. of Klengel H. 1984 (Keilschrifturkunden aus Boghazköi 54 Hethitische Rituale und Festbeschreibungen); ZA 75, 1985, 142-145.

Pecchioli Daddi, Franca, Mestieri Professioni E Dignità Nell'Anatolia Ittita, Roma: Edizioni dell'Ateneo, 1982.

Rüster, Christel- Neu Erich, Hethitischen Zeichenlexikon : Inventar und Interpretation der Keilschriftzeichen aus den Boğazköy-Texten, Wiesbaden: Otto Harrasowitz, 1989.

Taggar- Cohen, A. Hittite Priesthood (THeth 26) Heidelberg 2006.

Tischler, Johann, Hethitisches Handwörterbuch, Mit dem wortschatz der Nachbarsprachen Innsbruck: : Institut Für Sprachwissenschaft der Universität, Innsbruck 2001. 
Ünal, Ahmet, Multilinguales Handwörterbuch des Hethitischen / A Concise Multilingual Hittite Dictionary/ Hititçe Çok Dilli El Sözlügüu, Hamburg: Kovač 2007.

Ünal, Ahmet, Hititçe-Türkçe, Türkçe-Hititçe Büyük Sözlük, Hattice, Hurrice,

Hiyeroglif Luvicesi, Çivi Yazısı Luvicesi ve Palaca Sözcük Listeleriyle Birlikte, Ankara: Bilgin Kültür Sanat Yayınları, 2016.

Ünal, Ahmet, Hitit Başkenti Hattuša'da Otuz Bin Koyunlu, On Bin Boğall ve Bol Íçkili Büyük Şölen Eski Anadolu'nun 3500 Yıllık Yemek ve İçkileri, Ankara: Bilgin Kültür Sanat Yayınları 2019.

Ünal, Ahmet, Hititçe Dilbilgisi. Çivi Yazısı Işsaret Listesi ve Çok Sayıda Okuma Parçalarıyla Birlikte (Ankara: Bilgin Kültür Sanat Yayınları 2019.

Ünal, Ahmet, Hititlerde Din, Devlet, Halk ve Eğlence, Ankara: Bilgin Kültür Sanat Yayınları 2019.

Weeden, Mark, Hittite Logograms and Hittite Scholarship (StBoT 54) Wiesbaden: Harrassowitz Verlag 2011.

Wegner, Ilse Hurritische Opferlisten aus hethitischen Festbeschreibungen, Teil 1: Texte für ISTAR-Sa(w) uska (ChS 1/3/1) Roma 1995.

Yoshida, Daisuke Untersuchungen zu den Sonneingottheiten bei den Hethitern, Schwurgötterliste, helfende Gottheit, Feste, (THeth 22), Heidelberg: C. Winter 1996

\section{KISALTMALAR}

Bo

Inventarnummern von Tontafeln aus Boğazköy

$\mathrm{ChS}$ Corpus der hurritischen Sprachdenkmäler

$\mathrm{CTH}$ Laroche, Catalogue des textes hittites, Paris, 1971.

HED

Puhvel, Jaan, Hethitische Etymological Dictionary, Berlin/New York/Amsterdam $1984 \mathrm{vd}$.

HEG Tischler Johann, Hethitisches Etymologisches Glossar, Innsbruck 1977 vd.

HHW Tischler, Johann, Hethitisches Handwörterbuch, Mit dem wortschatz der Nachbarsprachen Innsbruck 2001.

HW Friedrich, Johannes, Hethitisches Worterbuch, Heidelberg 1952.

HZL Rüster, C.- Neu, E., Hethitische Zeichenlexikon. Inventar und Interpretation der Keilschriftzeichen aus den Bogazköy-Texten, StBoT Beiheft 2, Wiesbaden 1989.

JCS Journal of Cuneiform Studies

KBo Keilschrifttexte aus Boghazköi, Leipzig, Berlin 1916 vd.

KUB Keilschrifturkunden aus Boghazköi, Berlin 1921 vd.

Krş. Karşılaştırınız

ZA Zeitschrift für Assyriologie und Vorderasiatische Archäologie 


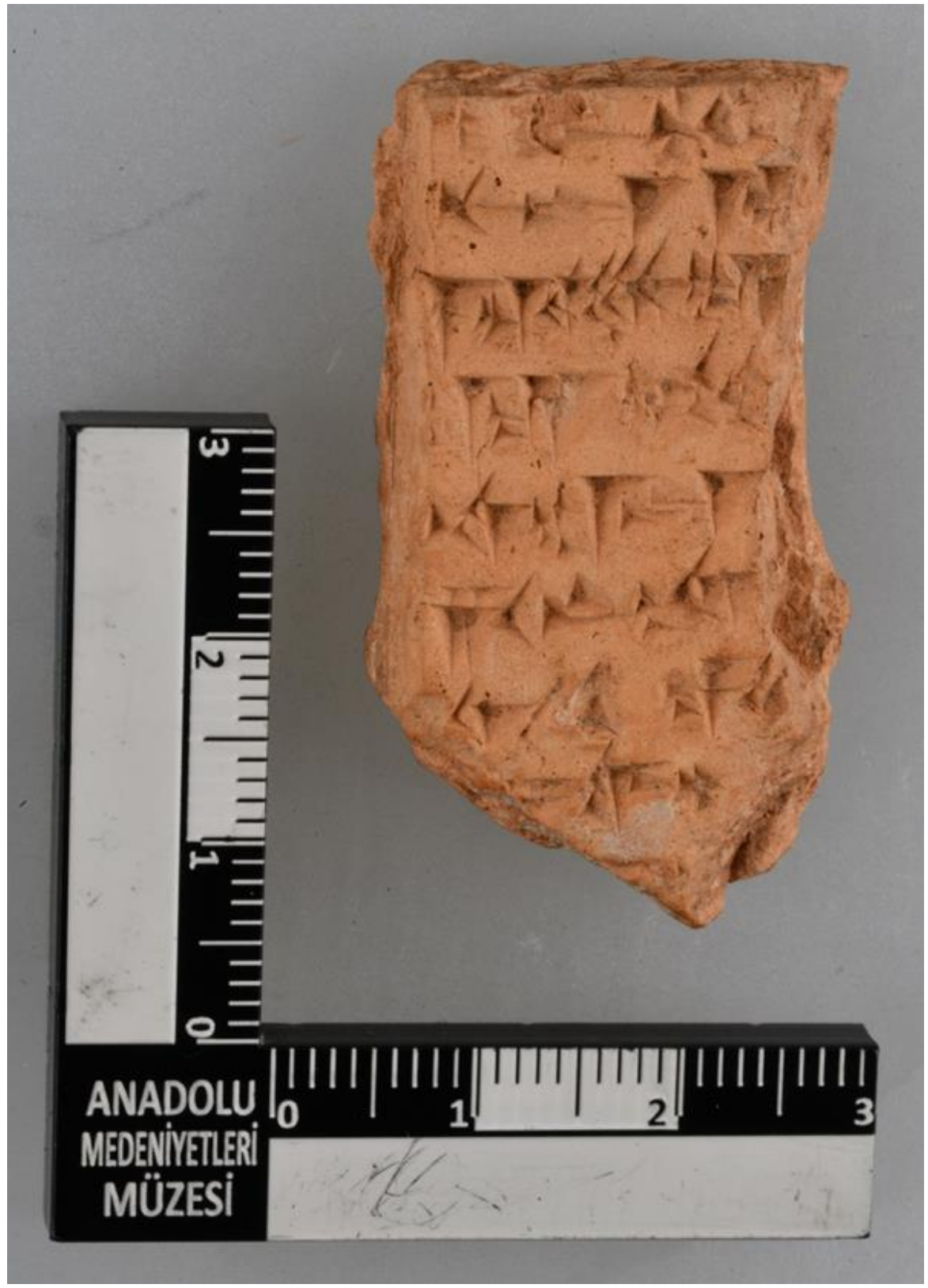

Res. 1. Bo 7825 


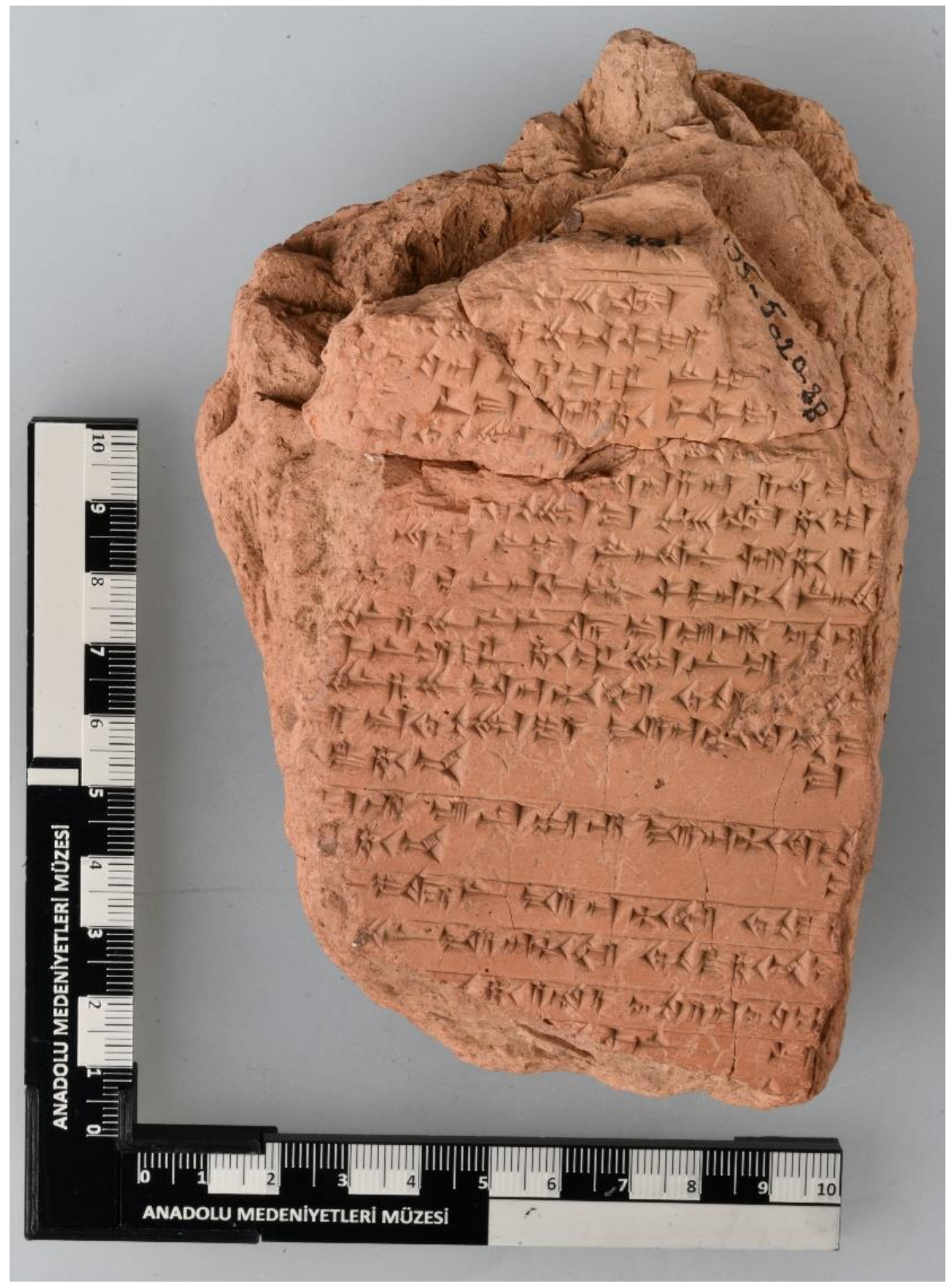

Res. 2. Bo 7881 


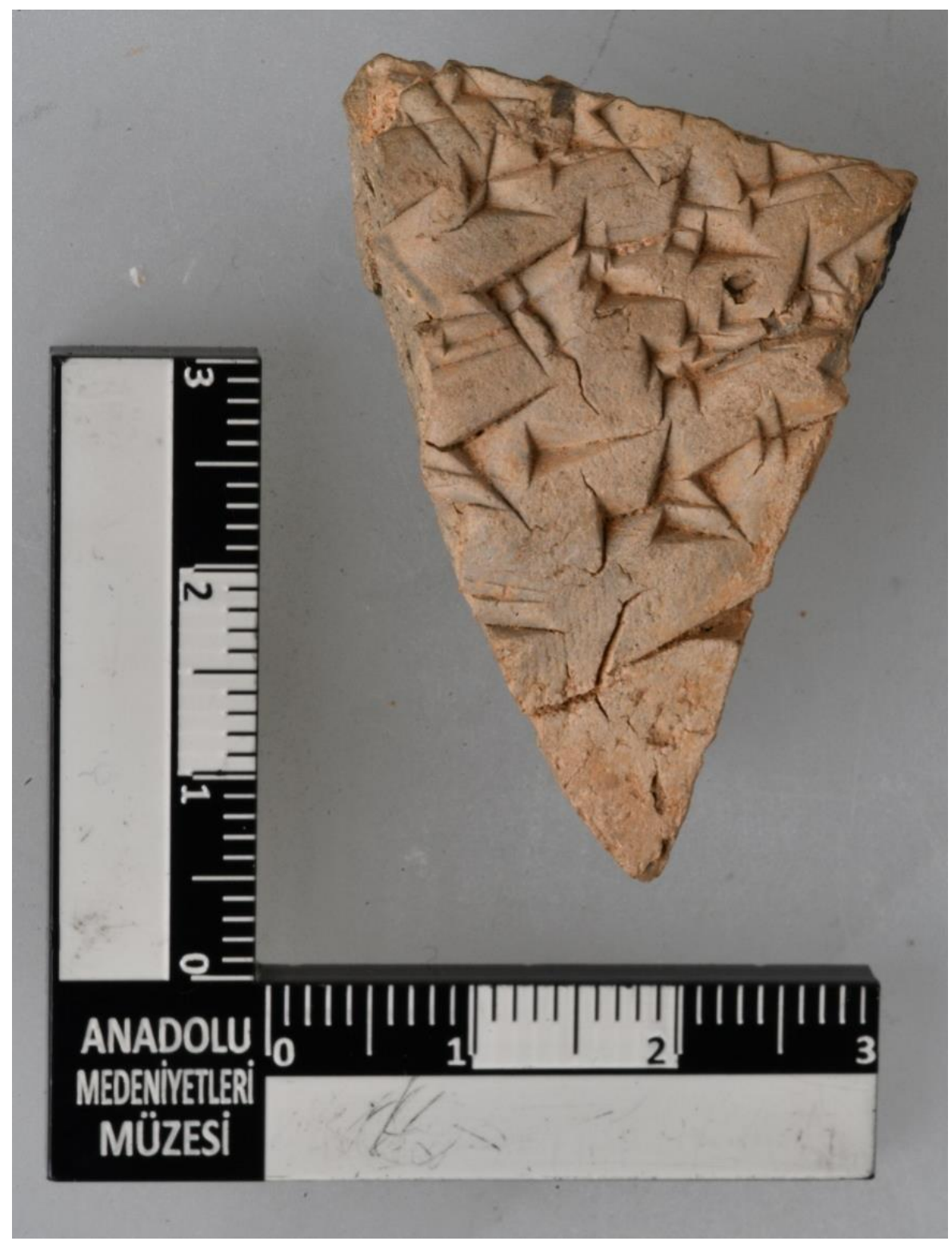

Res.3. Bo 8141 
430 BOĞAZKALE ARŞIVINDDEN YENİ HITITTÇE FRAGMANLAR
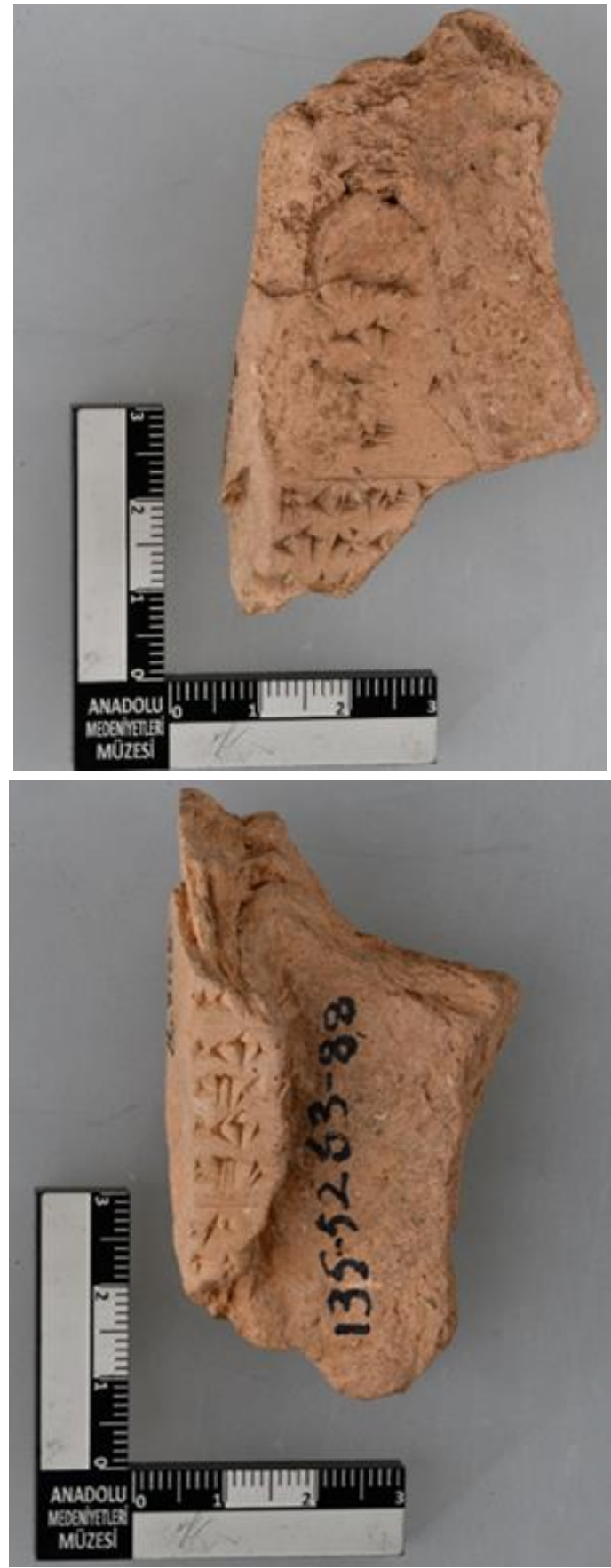

Res. 4. Bo 8168 öy. ve ay. 